\title{
COMMENTARY
}

\section{Crop Diversification for Sustainable Agriculture}

\section{Raj Paroda*}

\begin{abstract}
In India, over the years, the new cropping systems have become predominant in view of their higher productivity as well as income for farmers. Examples are rice-wheat cropping system in the north, groundnut in Gujarat, sugarcane in the north, chickpea in southern states, arhar in the north-western states, soybean in Madhya Pradesh and adjoining states, and winter maize in Bihar. Unfortunately, most of these systems require diversification for greater sustainability and conservation of natural resources. Time is ripe now to bring in needed reforms in the existing cropping systems that are more scientifically based and more suited to varying agro-climatic conditions. The possibilities of future crop diversification that can increase farmers' production as well as income and also ensure conservation agriculture through sustainable intensification are described in this commentary. There is a need for long term planning and development of various strategies for crop diversification in the best national interest.
\end{abstract}

Crop diversification, defined as the introduction or addition of new crops to the existing farming system, can occur at the individual farm level or at larger scales. It involves the practice of cultivating more than one variety of crops belonging to the same or different species in a given area through rotations and/or intercropping. It can be one of the most ecologically feasible, cost-effective, and rational ways of reducing uncertainties in agriculture-especially among smallholder farmers (Joshi 2005). Crop diversification also increases resilience, is more agronomically stable, and ensures greater spatial and temporal biodiversity in farms (Holling 1973; Joshi 2005). The resilience is due to factors such as reduced weed and insect pressures, less reliance on nitrogen fertilizers (especially if the crop mix includes leguminous crops), reduced erosion (because of the inclusion of

\footnotetext{
* Chairman, Trust For Advancement Of Agriculture, raj.paroda@gmail.com

Copyright (C) Paroda 2022. Released under Creative Commons Attribution (C) NonCommercial 4.0 International licence (CC BY-NC 4.0) by the author.

Published by Indian Society for Ecological Economics (INSEE), c/o Institute of Economic Growth, University Enclave, North Campus, Delhi 110007.
}

ISSN: 2581-6152 (print); 2581-6101 (web).

DOI: https://doi.org/10.37773/ees.v5i1.611 
cover crops), and increased soil fertility and yield per unit area (Lin 2011). Diversification can also enhance climate resilience (Economic Survey 201920) and conservation of natural resources (soil, water, and biodiversity) by replacing more exploitative approaches and focusing production systems on regenerative agriculture.

Traditionally, prior to the Green Revolution, agriculture was more diversified and sustainable when it came to crops and livestock, with silvipastoral systems and agroforestry approaches working with animal-based farming systems (Paroda 2019). Scientific advancements and options for improved varieties and new crops led to a shift towards a few crops having the potential to yield more and provide a higher income. Such an approach eventually narrowed down dependence to just a few crops like wheat, rice, maize, sugarcane, etc. Returning to higher crop diversification could contribute to all three main principles of climate-smart agriculture (CSA): improving productivity and livelihood outcomes, increasing the resilience and sustainability of farming systems, and reducing carbon dioxide emissions. Additionally, crop diversification has a positive impact on climate change due to increased carbon sequestration.

Crop diversification has helped attain more sustainable agriculture in other parts of the world. For example, the most sustainable cropping system accounts for $38 \%$ and $35 \%$ of maize and soybean production in the US, respectively, producing around 360.25 and $120.56 \mathrm{mt}$ in 2020 . Over $85 \%$ is produced in the north-central region known as the "Corn Belt", where twoyear maize-soybean rotation is the dominant cropping system (Grassini et al. 2015). Israel, once the world's leading fresh citrus producer and exporter, now grows more than 40 types of fruits including avocados, bananas, olives, apples, cherries, figs, plums, grapes, dates, strawberries, prickly pears, persimmons, loquats, and pomegranates. The fruit crops have eventually replaced wheat and cotton. Similarly, several varieties of dates were tried in Coachella valley in California, but 'Deglet Noor', an Algerian variety, became most popular, covering approximately $90 \%$ of the area under date cultivation in California today.

In the Green Revolution era (1967-68 to 1977-78), the major focus was on cereals (mainly rice and wheat). Over the years since then, fortunately, our food basket has started to diversify again, although more progress still needs to happen. The pattern of cropping has shifted mainly to more profitable crops like pulses, oilseeds, cotton, sugarcane, vegetables, fruits, and spices. At the state level, Andhra Pradesh, Maharashtra, and Gujarat seem to have the highest crop diversification followed by West Bengal, Bihar, and Karnataka. Most of the other states, especially Odisha, Madhya 
Pradesh, and the north-eastern states, are still confined to a few traditional crops.

There are two main types of agricultural diversification prominent in India: i) horizontal diversification (multiple cropping or mixing of crops instead of growing a single crop), and ii) vertical diversification (incorporation of industrialization along with multiple cropping, wherein farmers invest in supplemental activities like horticulture, agroforestry, livestock rearing, culture of aromatic plants, etc.).

Today, with regional diversification patterns, there is still a predominance of rice-wheat cropping systems in Punjab, Haryana, and Uttar Pradesh; groundnut in Gujarat; sugarcane in the north (mainly due to the nobilization of sugarcane by transferring both drought and disease tolerance from Saccharum spontaneum); chickpea in south India (due to the breeding of short duration varieties); pigeonpea (Cajanus cajan) in north-western states like Haryana, Punjab, Rajasthan, and Gujarat (due to early maturing varieties [120 days]); soybean in Madhya Pradesh and adjoining states; and winter maize in Bihar with very high productivity ( $>7.0$ tons/ha). Despite these dominant crops, there are still opportunities for shifting areas to short-duration varieties of chickpea (Cicer arietinum) in non-traditional areas of Andhra Pradesh, Bihar, Tamil Nadu, and Karnataka; mixed cropping of urd bean (Vigna mungo), mung bean (Vigna radiata), and pigeonpea in central and peninsular regions; introduction of short-duration pigeonpea in Gujarat, Rajasthan, Haryana, and Punjab; and lentils (Lens culinaris), mustard (Brassicaspp), and peas (Pisum sativum) in rice fallows in Bihar, West Bengal, Odisha, Assam, and some of the north-eastern states.

Currently, we are short of pulses in the country, and to achieve additional production, there is a need to breed and promote short-duration (less than 110 days) pigeonpea hybrids for the north-western region and improved varieties of soybean and kabuli chickpea for the north-western region; popularize improved short-duration, disease-resistant varieties of mung bean to fit rice-wheat cropping systems during summers in the north; and promote urd bean in rice fallows in the coastal regions of Andhra Pradesh, Odisha, and West Bengal. The decline in the production of sorghum and pearl millet is largely due to changes in dietary habits, low yields, and shifting of areas towards more remunerative crops such as cotton, soybean, wheat, oilseeds, and pulses. Though farmers have been cultivating sorghum (both in kharif and rabi) and pearl millet in rainfed areas, their production has been highly volatile largely due to low and erratic rainfall (Paroda 2006; 2018). These changes from traditionally grown, less remunerative crops to more productive crops that are ideally suited to some geo-climatic, socio- 
economic, and technological options have invariably been gradual. However, it primarily accelerated after India's Independence (1947) when cradles of success such as policy support, good institutions, human resources, and infrastructure were put in place.

The current challenge is to breed early hybrids to replace HHB67 in the very dry region (A1 zone) in Rajasthan, and varieties/hybrids of rabi sorghum to replace the predominantly cultivated older variety, "Maldandi", in Maharashtra. Introducing quality protein maize (QPM) hybrids suited to different agro-climatic zones, and improving coverage of the area under single cross maize hybrids, will further enhance maize production. For future diversification, pseudocereals (grain amaranth, buckwheat, and quinoa), legumes (rice bean, faba bean, adzuki bean, and moth bean), and small millets (finger millet, foxtail millet, proso millet, little millet, barnyard millet, and kodo millet) having high nutritional value and niche for high drought and heat tolerance have considerable potential. Soybean, popular in Madhya Pradesh and Maharashtra, has the potential to replace rice to some extent in north India. There is a need to promote the cultivation of specific crops in new niches to harness their maximum genetic potential (Paroda 2019).

Past experiences have amply demonstrated that expansion of crops in nontraditional, newer areas can lead to more rapid progress in diversification due to faster adoption of full technological packages without any preexisting prejudices from traditional practices. Some good examples of this are puddled rice in north India, use of wide permanent rows for groundnut planting in Gujarat, cultivation of soybean in Madhya Pradesh, rabi maize in Bihar, etc. Such an approach is most beneficial when it is based on scientific land-use practices.

Other good examples of diversification are hybrid rice in eastern India, soybean in the eastern and north-eastern regions, and, to some extent, sunflowers in north India. After Brazil, India is the second-largest producer of sugarcane in the world. It has the best R\&D infrastructure and is known globally for nobilization of sugarcane resulting in short-duration, droughtand disease-tolerant varieties, which enabled its spread to central, northern, and western India. Earlier, productivity in Uttar Pradesh, Haryana, Punjab, and Maharashtra was even lesser than the national average despite the availability of good varieties and production technologies. With increasing area under a new variety (CO238), the scenario for productivity and sugar recovery has changed significantly. The yield potential of maize can also be enhanced significantly by bringing more area under single cross hybrids that 
are high yielding. Its extension to eastern Uttar Pradesh, Bihar, Jharkhand, and West Bengal is already taking place (Paroda 2019).

Crop diversification largely depends on technological innovations aimed at sustainable intensification and increased productivity while reducing the cost of inputs so as to raise the income of farmers. The dynamic aspect of diversification includes the accommodation of new crops or cropping systems that are best suited to prevailing eco-regional conditions while ensuring higher production and income. By growing a variety of crops, farmers lower their risk and can gain access to national and international markets. Agricultural intensification has helped us achieve food security in the past, but now we need to reorient existing cropping systems to be more sustainable and to continue addressing our household food, nutrition, and environmental security.

It is necessary to develop a shared conceptual understanding of diversification. Often, terms such as diversity, diversification, crop rotation, and mixed cropping are used interchangeably, preventing generalization of results. The crop diversification approach provides information on (i) problem definition, (ii) baseline definition, (iii) scale definition, (iv) characterization of the experimental design including a minimum set of target variables, and (v) defining the impact systematically to assess and report the effects of the diversification measures.

The main challenges facing agricultural diversification are land degradation, a decline in soil health, groundwater depletion, environmental pollution, and a decline in total factor productivity. These constraints must be addressed if existing cropping systems are to be made both more sustainable and remunerative for farmers.

Farmers need to be continuously motivated and encouraged to pursue crop diversification for better sustainability as well as income and employment opportunities. Given that an accelerated pace of diversification will have positive impacts on income, employment, conservation, and use of natural resources, there is a need for increased investment in R\&D and scaling of innovations linked to sustainable farming systems that are best suited to varying agro-ecologies. However, while adopting crop diversification, cultivators must ensure that it does not adversely affect the existing environmental balance concerning available natural resources.

For crop diversification, future strategies must aim at: i) horizontal approaches that integrate crop intensification and crop substitution with species that are most suited to specific eco-regions; ii) vertical approaches for enhancing productivity using genome editing and good agronomic 
practices (GAP) aimed at judicious use and increased efficiency of costly inputs such as water, energy, fertilizers, and pesticides; iii) post-harvest processing, value addition, branding, packaging, etc. to enhance income; iv) water-use efficiency through micro-irrigation, especially in drylands; v) varietal diversification introducing both high-yielding varieties and hybrids for higher productivity; vi) incorporation of legumes; vii) large-scale adoption of integrated pest management; and viii) risk management through inter-cropping and mixed cropping, a shift towards low-volume high-value crops, and mixed farming. Such an approach would require scaling of innovations to improve resource-use efficiency through appropriate policies and programmes. In this context, scientific land-use planning so far has been a weak link. Fortunately, vast opportunities in unexplored frontiers of science exist with potential for new gains from the application of science, technology, and innovation (STI) for sustainable agricultural growth and development.

There is a need for further diversification around local food systems, as has been emphasized by the UN Food Systems Summit held in September 2021 and the second International Agrobiodiversity Congress (IAC) organized in October 2021. COVID-19 has further highlighted this particular requirement for crop diversification for greater sustainability of agricultural production systems, as well as for household nutrition security and improved health and immunity. Required actions include: i) ensuring access to safe and nutritious food for all; ii) shifting to sustainable consumption patterns; iii) boosting nature-positive, eco-region-specific production; iv) advancing equitable livelihoods; and $\mathrm{v}$ ) building resilience against vulnerabilities, shocks, and stress.

India needs the right mix of policies, moving from subsidy-driven to investment-driven, from price-focused to income-focused, and from exploitative to sustainable agricultural diversification around more nutritious food. It also needs to incentivize the private sector, especially young entrepreneurs, to build efficient and inclusive value chains for farmers' prosperity, giving due importance to environmental sustainability.

\section{REFERENCES}

Economic Survey. 2019-20. "Economic Survey 2019-20 - Volume 1 January 2020)." New Delhi: Department of Economic Affairs, Ministry of Finance, Government of India. 
Grassini, Patricio, James E Specht, Matthijs Tollenaar, and Ignacio Ciampitti. 2015. "High-yield Maize-Soybean Cropping Systems in the US Corn Belt." Crop Physiology: 17-41. https://doi.org/10.1016/B978-0-12-417104-6.00002-9

Holling, Crawford Stanley. 1973. "Resilience and Stability of Ecological Systems." Annual Review of Ecological Systems 4 (1):1-23. https://doi.org/10.1146/annurev.es.04.110173.000245

Joshi, P. 2005. "Crop Diversification in India: Nature, Pattern and Drivers." New Delhi, India: Asian Development Bank.

Lin, Brenda B. 2011. "Resilience in Agriculture Through Crop Diversification: Adaptive Management for Environmental Change." Bioscience 61 (3): 183-193. https://doi.org/10.1525/bio.2011.61.3.4

Paroda, RS. 2006. "Strategy for Increasing Productivity Growth Rate in Agriculture." Strategy Paper for the Planning Commission, Government of India for the proposed draft XI Five-Year Plan (submitted on 12th July 2006). New Delhi: Trust for Advancement of Agricultural Sciences.

Paroda, RS. 2018. "Reorienting Indian Agriculture: Challenges and Opportunities." Oxfordshire: Centre for Agriculture and Bioscience International (CABI). https://doi.org/10.1079/9781786395177.0000

Paroda, RS. 2019. "Report on Policies and Action Plans for a Secure and Sustainable Agriculture." New Delhi: Committee Report submitted to the Principal Scientific Adviser to the Government of India. 